\title{
Analysis of the Inheritance and Development of Sichuan Ethnic Minorities' Traditional Sports Culture
}

\author{
Zheng Zhong Fan \\ Institute of Physical Education, \\ Neijiang Normal University \\ NEI JIANG, CHINA \\ E-mail: 250814033@qq.com
}

\author{
Sun Liang Liang \\ Institute of Physical Education \\ Sichuan University of Arts and Science \\ DA ZHOU, CHINA \\ E-mail: sunliang6@126.com
}

Keywords: Sichuan's ethnic minorities; Traditional sports; Cultural inheritance; Development

\begin{abstract}
With the constant development and progress of China's society, people nowadays are gradually paying more attention to the inheritance and development of traditional sports culture. This paper discusses the inheritance and development of Sichuan Ethnic minorities' traditional sports culture from the inheritance ways, current development and development strategies.

Against the backdrop of current economic and social development, people begin to pay more attention to the cultural value, entertainment value and economic value of traditional ethnic sports. Meanwhile, the government also attaches great importance to these traditional ethnic sports and include more traditional ethnic sports into the list of national intangible cultural heritage and the expanded directory to protect them. Although there are very rich traditional sports resources in ethnical groups in Western China, few of them have been listed into the national heritage list, only less than $20 \%$, which indicates that the inheritance of ethnic minorities' traditional sports culture in China, especially in Sichuan province needs to be constantly strengthened. Therefore, it is of very important practical significance to inherit and develop traditional sports culture of ethnic minorities in Sichuan.
\end{abstract}

\section{Introduction to Traditional Sports Culture of Ethnic Minorities in Sichuan}

Main Contents of Traditional Sports Culture of Ethnic Minorities in Sichuan. Located at Southwestern China, Sichuan has gathered a large part of ethnic minorities in China, such as the Tibetan, Qiang, Yi, Miao, etc., altogether 14 ethnic minorities. Meanwhile, Sichuan has the most Yi people in China and the total number of Tibetan people ranks the second nationwide. Besides, Sichuan is the only place with Qiang ethnic minorities in China. There are a large number of ethnic minorities in Sichuan, totally more than 4.3 million. Some surveys show that these ethnic minorities have passed down rich traditional sports resources, which can not only enrich people's life, but also reflect their attitudes and values with various functions like fitness and entertainment.

Basic Features of Traditional Sports Culture of Ethnic Minorities in Sichuan. There are many ethnic minorities in Sichuan, but each ethnic minority has its unique national culture with great differences in economic foundation and customs, so the traditional sports culture of each ethnic minority differs from each other. However, as all of them are ethnic minorities, they share some common basic features in traditional sports culture, which are mainly reflected in the several following aspects:

(1) History. Traditional culture is not a short period of time can be formed, but need to experience a long time in the process of historical development, which is formed by the it contains a very rich cultural, economic, social and political content and thought. Similarly, Sichuan minorities traditional sports is only gradually formed after a long time, and sports skills and sports entertainment, art, appreciation for the integration of cultural products, it not only contains abundant cultural information, as well as in part reflect the minority people's way of thinking, sensibility and values.

(2) Regional. Because ethnic minority people in Sichuan natural environment and cultural background are almost the same, plus minorities live migration ability, the absorption and 
assimilation of ethnic culture and so on a variety of reasons, also let the Sichuan minority people's traditional sports activities have many similarities, and some are the same, such as mountain climbing, wrestling, penetrating crossbow, pole and so on, these sports activities are common in every nation in Sichuan. It also suggests that the traditional sports activity belongs to this area in Sichuan, and not just a nation characteristic, therefore the Sichuan region characteristics of traditional minority national sports culture.

(3) Ethnic. Sichuan traditional minority national sports activities are not exist independently, but is closely related with people's life, farming and so on, at the same time, these sports activities need people to actively participate in, and on the basis of people's festival, activities such as inheritance. Sichuan minority has a relatively rich national holiday, despite the various national holiday in customs, activity time, content, significance and so on are different, but the traditional sports activities of the memory of customs and habits and customs, mode is consistent, at the same time, through the traditional sports activity also can better to make effective inheritance minority cultural and sports activities.

(4) Entertainment. Sichuan traditional minority national sports, whether in sports or physical activity forms are diversified, and there are also some sports athletics, but overall, these traditional sports have a strong entertaining, and entertaining than competitive. In the traditional sports activities in Sichuan, there are a lot of sports activities or cultural and artistic performance activities, and the original purpose of these activities is for entertainment, have a plenty of entertainment performances for everybody, have a plenty of participate in activities themselves entertainment, and some both these two features. All in all, these activities are in the business of life, entertainment and sports activities, not only can achieve the purpose of the sports activities, can also create a more joyful sports atmosphere.

(5) Common. Traditional minority national sports in Sichuan has the most important mass base, these traditional sports is a long-term production and practice of every nation, and involve the crystallization of the wisdom, the production of every nation, these traditional sports activity also can better reflect the traditional culture of every nation. Sichuan traditional minority national sports activities, there are a lot of activities are requires a collective participation, some activities need the whole village or even a few village people to participate, oppose each other in sports activities is less.

(6) Simple. Because Sichuan is located at remote areas, most traditional sports of ethnic minorities are very simple: some are produced on fields, some are produced on woodlands, and some are even in front of people's home with special field for neither sports nor special sports facility. Farming people can use their own devices, can also use the mountain has its own object, etc., these are common, and more convenient to popularize. At the same time, these sports and more convenient to implement, to places and equipment requirements is not high.

\section{Ways to Inherit Traditional Sports Culture of Ethnic Minorities in Sichuan}

Traditional sports of ethnic minorities in Sichuan are passed down over time depending on people of each ethnic minority, and if the inheritance is interrupted these sports cannot be effectively inherited, which means the extinction of traditional sports. Sichuan traditional minority national sports culture with the major language of expression, transfer and personal mission of sports heritage, heritage through this makes these sports activities, such as culture, skills can be preserved, generation of circulated, also because of the traditional sports activity of descendants, makes the intangible cultural heritage get complete development and preservation. "Precept" can be simply interpreted as words and the teaching content. And content is also different, both contains words refers to using language to express the related content of sports activities, sports activities and to demonstrate being taught some skills and techniques, tend to sports theory and the skill itself, but is physically give to being taught some skills and techniques of effective teaching and guidance, focused on sports activities for learning by being taught the understanding and comprehension. 
Precept is an efficient way of inheritance, and its traditional minority national sports in Sichuan has a very important role in cultural inheritance, by inheriting by inheriting the precept can better understand and learn, master, the traditional sports activities and sports activities contained in the sports culture. Held at the same time, the minority ritual activities or some celebrations, it will also have a wizard as a mentor to relevant skills, supervising the custom, history and related cultural mission, and their children will consciously to carry on the imitation and study, so that the traditional sports activities will be effective.

\section{Current Development of Inheriting Traditional Sports Culture of Ethnic Minorities in Sichuan}

Changes of Lifestyles Restrict the Healthy Development of Traditional Sports of Ethnic Minorities. With the rapid intensification of global economic globalization and integration, great chances have taken place in the lifestyle and customs of ethnic minorities in Sichuan. All these concrete changes will restrict the healthy development of traditional sports and culture of ethnic minorities to varying degrees. Traditional sports are closely related to the production and lifestyle of people and some directly derivate from people's labor and production ways, such as bamboo jumping, swinging, and bullfighting, etc. These changes of lifestyles will inevitably restrict the healthy development and effectively inheritance of traditional sports culture of ethnic minorities.

Single and Backward Inheritance Ways Make it Difficult to Effectively Inherit Traditional Sports of Ethnic Minorities. Currently, the main way to pass down traditional sports of ethnic minorities in Sichuan is "by words and deeds". Although this way plays an important role in inheriting traditional sports and can also enrich people's cultural life and entertain them, from the perspective of inheritance, this way of inheritance is relatively single and backward. Without systematic inheritance channels or advanced and scientific inheritance technical means, it is hard to adapt to the demands of developing modern society. Meanwhile, there are more and more cultural and entertainment activities in modern society and they are becoming increasingly diversified, corresponding ethnical festivals will reduce, making it hard to effectively inherit traditional sports of ethnic minorities.

The Rapid Development of Modern Sports Gradually Marginalizes Traditional Sports of Ethnic Minorities. At present, modern sports have been developing well in China. Not only a systematic theoretical system has been formed, but also various high-tech means can be used to better satisfy people's demands for sports, promoting the market, industrialized and diversified development of sports in China. Meanwhile, the rapid popularization and development of education in China has also enabled various modern sports like basketball, football and swimming to enter ethnic minority communities and schools in Sichuan. Besides, all these modern sports are well received among ethnic minority students and are gradually becoming a mainstream among students. Although traditional sports are also popular among students, they are not so elegant. In addition, traditional sports of ethnic minorities in Sichuan are not so competitive, so it is hard for them to be included into regular sports competition, making it even harder to promote them. Consequently, they are gradually marginalized.

Traditional Sports Organizing and Management Mechanism is Backward, Hindering the Healthy Development of Traditional Sports Culture. Ethnic minorities in Sichuan locate at remote areas with inconvenient traffic and backward economy as well as backward mechanism to organize and manage traditional ethnic sports and little support from local government. Meanwhile, each ethnic group in Sichuan has few traditional ethnic sports activities with limited fields for sports as well as backward and old sports facility. Some are even bad. Besides, some traditional sports of ethnic minorities in Sichuan are even neglected and ignored. All these will restrict the healthy and orderly development of traditional sports and culture. 


\section{Strategies to Inherit and Develop Traditional Sports Culture of Sichuan Ethnic Minorities}

Strengthen Relevant Local Government's Support and Protection of Traditional Ethnic Culture. The inheritance and development of traditional ethnic sports culture is the work of the entire nation, so it is necessary to strengthen relevant local governments' vigorous support and protection of traditional ethnic sports culture. Only this way can ensure the effectively inheritance of traditional sports culture of ethnic minorities. First of all, government at all levels should emphasize the development of traditional ethnic sports, increase investment in this field and formulate some feasible referential policies to vigorously support the development of traditional ethnic sports culture. Secondly, related departments should strengthen publicity and avocation of inheriting traditional ethnic sports and include them into important contents of physical education, fitness and the development of tourism in Sichuan. Finally, effective cooperation between sports, education, culture and relevant departments should also be strengthened so as to guarantee the effective protection and inheritance of traditional ethnic sports culture.

Actively Develop Traditional Ethnical Sports at Universities and Colleges at Each Ethnic Regions in Sichuan. The research base of universities should be made full use of to actively carry out traditional ethnic sports. Also, we can also establish "ethnic minorities' traditional sports culture research and inheritance experiment base", regularly conduct some academic researches and communication, emphasizing on checking and recording traditional sports and culture resources of Sichuan ethnic minorities and finding our the development of these traditional sports to find corresponding strategies to effectively protect and inherit traditional sports culture.

Introduce Traditional Sports of Ethnic Minorities into Schools to Effectively Combine Traditional Sports Culture and Physical Education. Schools of each ethnic minority in Sichuan should effectively introduce traditional sports of ethnic minorities into their physical education so as to effectively combine traditional sports culture with physical education. Schools can also add some traditional ethnic sports appropriately into their teaching program of each semester, formulate uniform syllabus and teaching plan, and establish correct sports training system so as to guarantee the effectively spread of traditional ethnic sports among teenagers.

Effectively Combine with National Fitness to Promote Traditional Sports of Ethnic Minorities to Gradually Enter People's Daily Life. An important direction of developing China's mass sports is to realize mass fitness, so it is necessary to effectively combine traditional sports culture of ethnic minorities and mass fitness so as to promote the development of traditional sports culture of ethnic minorities in China to become more integrated with people's daily life. Some traditional sports that can serve for both fitness and recreation such as martial arts and swing can be refined to fitness programs including fitness and recreation, so as to promote traditional sports of ethnic minorities to people's daily life and realize the purpose of integrating traditional sports of ethnic minorities into people's daily life.

Actively Develop Traditional Ethnic Sports and Tourism Resources to Further Promote the Development of Traditional Ethnic Sports Industry. The development of ethnic minorities' traditional sports industry will inevitably promote the rapid development of local economy because it can not only better inhibit the homogenization of the world's sports culture, but also promote the diversified development of ethnic minorities' traditional culture. Therefore, it is necessary to actively develop traditional sports and tourism resources of ethnic minorities in Sichuan. Only in this way can we promote the healthy development of local tourism and further promote the industrialized development of traditional ethnic sports so as to realize the co-development of ethnic minorities' tourism and traditional sports culture.

After all, ethnic minorities in Sichuan have very rich traditional ethnic sports culture and all these sports cultures have been undergoing a long period of precipitation. They can not only strengthen people's physique, but also represent the development of each ethnic minority's culture. However, the current development of traditional sports culture of Sichuan ethnic minorities is not so ideal, so corresponding strategies of development should be adopted to promote the effective inheritance of 
these traditional ethnic sports culture, thus promoting the healthy and scientific development of traditional sports culture of Sichuan ethnic minorities.

\section{Acknowledgements}

Fund Project: The general project of Education Department in Sichan （Number: 13SB0002）

\section{Reference}

[1] Li Shan Research into the Inheritance and Development of Traditional Sports Culture of Ethnic Minorities in Sichuan [J]. Journal of Southwestern Normal University (Natural Science Edition), 2011, 36(4):164-167.

[2] Li Ling. Conception of Developing Traditional Sports and Tourism of Ethnic Minorities [J]. Journal of Physical Education, 2010, 17(6):89-92.

[3] Xiao Mouyuan, Wei Xiaokang. Research into Path to Inherit and Educate Traditional Sports Culture of Ethnic Minorities [J]. Journal of Southwestern Normal University (Human Science Edition), 2014,(7):218-221.

[4] Yang Shiyong, Xu Lunzhan, Huang Bo, etc. Research into the Dilemma and Countermeasures of Developing Traditional Sports of Ethnic Minorities in Sichuan - Take on-horse Sports as an Example [J]. Journal of Chengdu Institute of P.E., 2012,38(1):56-59.

[5] Shao Yuping. Inheritance and Protection of Traditional Sports Culture of Ethnic Minorities Take an example of "White-horse Tibetan Group" at Tielou Village, Wen County, Southern Gansu [J] Journal of Lanzhou College of Arts and Science (natural science edition), 2014,28(6):68-70 